\title{
First Presentation of Breast Cancer in Patients Presenting to Health Care Facilities of Bahawalpur
}

\author{
Asima Luqman, Asiya Shabbir, Muhammad Sajid, Shahid Hussain, Hafiz Muhammad Usman Ali Rizvi, Summaira Hassan
}

\begin{abstract}
Background: There is an increased incidence of breast tumors worldwide. It is the second leading cause of death and disability related to cancer among females. High case fatality rates seen in resource-limited countries is due to a lack of awareness of the screening in the general population and inadequate facilities for early detection and poor access to health care facilities for treatment. Objective: The objective of our study was to determine the frequencies of different types and stage breast cancer at first presentation of the patients to a health care facility. Study Design: Descriptive CrossSectional Study. Settings: Study was conducted in two Government hospitals, Bahawal Victoria and Civil Hospital of Bahawalpur Pakistan. Duration: Six months (Jan 1, to June 30, 2019). Methodology: Total of 95 patients presented with breast cancer to the respective hospitals. After taking informed verbal consent from the patients the questions regarding their personal biodata were asked from them. Examination and surgical details were taken from their medical chart records. The data was analyzed with SPSS. Results: The mean age of the parents was 49.5(+11.6 SD) years. TNM staging of the patients showed that most of the patients were already in stage III (49.4\%) of breast cancer. Infiltrative ductal carcinoma was the most frequently occurring cancer,66 (69.4\%). Conclusion: Education about breast cancer awareness to female population could be helpful in early detection of cancer. Keywords: First presentation, Breast CA, Early diagnosis, Cancer staging.
\end{abstract}

DR. MUHAMMAD SAJID, Senior Registrar of Surgery, Bahawal Victoria Hospital, Bahawalpur-Pakistan.

Contact / Email:+92 321-6805751, drmsajid76@gmail.com

Citation: Luqman A, Shabbir A, Sajid M, Hussain S, Rizvi HMUA, Hassan S. First Presentation of Breast Cancer in Patients Presenting to Health

Care Facilities of Bahawalpur. APMC 2019;14(1):13-5.

\section{INTRODUCTION}

There is an increased incidence of breast tumor worldwide. ${ }^{1}$ It is the second leading cause of death and disability related to cancer among females. ${ }^{2}$ Developed countries have regularized breast cancer diagnosis since 1980. Unfortunately, it is not happened in the developing countries and as a result there is a rise in the incidences and associated mortality with breast neoplasms. This situation is predicted to worsen in the following years. ${ }^{3}$

Due to the lack of a proper cancer registration system at National level, the information regarding morbidity and mortality of breast cancer in Pakistan is inadequate. From the data obtained from different sources, it has been observed that approximately one in every $9^{\text {th }}$ Pakistani female will suffer from breast cancer in her lifetime making it one of the highest occurrence rates in Asia. ${ }^{4}$ Despite a very similar cultural and social environment, the incidence of breast cancer among Indian females $(19 / 100,000)$ significantly lower than that of its neighboring Pakistani women $(50 / 100,000) .{ }^{1}$ Frequency of luminal $B$ breast cancer is greater than luminal $A$ cancers in Pakistani population. ${ }^{5}$

The rise seen in the incidence of breast cancers in many lowincome countries is most likely due to changes in lifestyle, reproductive factors and increase in the life expectancy. An interplay of many factors including hormonal, genetic and environmental operating over a long period of time make its etiology very complex. ${ }^{2}$

Variations in incidence of breast cancer among multi-culture populations suggest that etiological factors vary in biological expression and their impact on disease outcome.
Early menarche, nulliparity, late first child birth, reduced parity, shorter duration of lactation and late menopause, as well as, no regular physical activity are associated with increased risk. An association has been observed in obesity and increased risk of

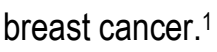

Late stage diagnosis of breast neoplasms leading to a predictably poor treatment outcome are usually due to a lack of public awareness. This will affect the disease-free survival markedly. Available data on stage at diagnosis in Pakistan is scarce, but indicate a very high proportion of cases detected in late stages i.e. usually $71 \%$ present in stage $1 \mathrm{III} .{ }^{6}$ In contrast to the developed countries where the majority of cases are detected in localized stage I and II of the disease, followed by regionally advanced stage III and distant-stage metastasis in only $5 \%$. High case fatality rates seen in resource-limited countries is due to a lack of awareness of the breast cancer screening in the general population and inadequate facilities for early detection and poor access to health care facilities for treatment. ${ }^{2}$

Guidelines that exist for the early diagnosis and prompt treatment of breast cancer in the developed countries could not be implemented in many of the low-income countries due to financial and health systems barriers.

The most widely adopted method for screening of breast neoplasm is mammography. However, in the developing world including Pakistan the use of population-based mammography for screening is currently too costly to implement and sustain. Breast self-examination education and clinical assessment may be an important method for early detection of breast cancer in the developing world. ${ }^{7}$ 
While reducing the incidence of breast cancer is an ideal goal, the options for achieving this are limited. Owing to its high prevalence, diverse and late stage presentation followed by an adverse outcome this disease needs to be addressed. Every effort should be made to increase the awareness of general public toward screening and self-examination. Data on the stage of first presentation of breast cancer in the Southern Punjab is scares so this study was conducted to aid in the existing knowledge of the stage of presentation of breast cancer.

\section{METHODOLOGY}

Study Design: Descriptive Cross-Sectional Study.

Settings: This study was conducted in two different government hospitals, (Bahawal Victoria and Civil Hospital) of Bahawalpur Pakistan.

Duration: Six months from January 1, 2019 to June 30, 2019. Sample Technique: Non-probability purposive sampling Sample Size: 95 participants. These were the patients presenting with breast cancer in the study duration fulfilling the selection criteria.

Inclusion Criteria: Willing female patients.

Exclusion Criteria: Patients with co-morbidities or with recurrence of breast tumor.

Methods: Data was collected on a pre-tested pre-formed questionnaire. It consists of 2 parts. Part A was about of personal biodata of the patient and part $B$ included the questions pertaining to the study. After taking informed consent from the eligible patient's questions were asked from the subjects in the local language. Then the answers were retranslated in English and filled in the Performa by the researcher. Data for the triple assessment and the surgical details were entered from the medical record sheet of the patient by the researcher.

Data Analysis: Data was analyzed by using SPSS version 21.

\section{RESULTS}

A total of 95 patients presented with breast cancer to the health care facility in the study duration. The mean age of the patients was $49.5(+11.6 \mathrm{SD})$ years. Maximum number of the subjects were in the age group of 50-64 years i.e. 37 (38.9\%) (Table 1)

Table 1: Age distribution of the patients

\begin{tabular}{|c|c|c|}
\hline Age groups (years) & Frequency & Percentage $\%$ \\
\hline $\mathbf{2 0 - 3 4}$ & 8 & $8.4 \%$ \\
\hline $\mathbf{3 5 - 4 9}$ & 36 & $37.8 \%$ \\
\hline $\mathbf{5 0 - 6 4}$ & 37 & $38.9 \%$ \\
\hline $\mathbf{6 5 - 7 9}$ & 14 & $14.7 \%$ \\
\hline
\end{tabular}

Table 2: Staging of cancer in the patients

\begin{tabular}{|c|c|c|}
\hline Stage & Frequency & Percentage $\%$ \\
\hline I & 3 & $3.1 \%$ \\
\hline II & 25 & $26.3 \%$ \\
\hline III & 47 & $49.4 \%$ \\
\hline IV & 20 & $21.0 \%$ \\
\hline
\end{tabular}

$50(52 \%)$ of the patients belonged to urban localities of Southern Punjab.
All the patients went through triple assessment to help in reaching to a diagnosis and their treatment plan. TNM staging of the patients showed that most of the patients were already in stage III (49.4\%) of breast cancer. (Table 2)

These patients were subjected to FNAC / Core biopsy for pathological assessment. Infiltrative ductal carcinoma ,66 $(69.4 \%)$ was the most frequently occurring cancer. (Table 3 )

\section{Table 3: Frequencies of different tumor types}

\begin{tabular}{|l|c|c|}
\hline \multicolumn{1}{|c|}{ Type of cancer } & Frequency & Percentage \% \\
\hline $\begin{array}{l}\text { Infiltrative ductal } \\
\text { carcinoma }\end{array}$ & 66 & $69.4 \%$ \\
\hline $\begin{array}{l}\text { Infiltrative lobular } \\
\text { carcinoma }\end{array}$ & 23 & $24.2 \%$ \\
\hline Carcinoma in situ & 4 & $4.2 \%$ \\
\hline $\begin{array}{l}\text { Squamous cell } \\
\text { carcinoma }\end{array}$ & 2 & $2.2 \%$ \\
\hline
\end{tabular}

\section{DISCUSSION}

Breast cancer is the commonest female neoplasm all over the World including Pakistan making it a public health problem and is second leading cause of female deaths owning to its late presentation for medical advice. ${ }^{8}$

In our study, the mean age of the subjects was 49.5 (+11.6 SD) years which is comparable to the studies conducted in Rawalpindi, Karachi and Lahore being 46.0 (+12.0 SD) , 47.5 $(+12 \mathrm{SD})$ and $48.6(+12 \mathrm{SD})$ respectively. ${ }^{9-11}$ Literature from studies conducted in Mexico and Iran also showed similar age patterns ,50.9 (+13.7 SD0, 47.0 (+11.3 SD) and $47.9(+9.4$ $\mathrm{SD}) .^{12,13}$

Most of the study subjects fell in the age group of 50-69 years (38.9\%) comparable to study conducted in United Kingdom where most commonly occurring age group was 50-69 years (37\%). ${ }^{14}$ A study conducted in Bahawalpur showed similar results, where $53(42.1 \%)$ participants were is the age group more than 40 years. ${ }^{1}$

The most common stage of breast cancer at first presentation in our study was stage III (49.4\%) followed by stage II (26.3\%). Similar patterns were seen in studies conducted in Rawalpindi 9 and Malaysia ${ }^{16}$ where stage III was the most common presentation of the patients. ( $53.8 \%$ and $44.8 \%$ respectively). Patients with stage II disease were $38.7 \%$ in Malaysia ${ }^{15}$ making it the second frequently presenting stage of the disease.

In our study infiltrating ductal carcinoma 66 (69.4\%) was the most frequent type of cancer on histopathology followed by infiltrating lobular carcinoma. Literature supports our results by showing similar patterns in most places. Studies conducted in Rawalpindi ${ }^{9}$ showed that $82.8 \%$ of their patients had infiltrative ductal carcinoma as the most common type of cancer. Data from Lahore ${ }^{11}$ and Malaysia ${ }^{15}$ also showed comparable patterns $(86.6 \%$ and $89.3 \%)$. Whereas carcinoma in situ was $1.4 \%$ in a study conducted in Lahore ${ }^{11}$ and $4.6 \%$ in our study.

\section{CONCLUSION}

Education about breast cancer awareness to female population, advocacy about curability, increased coverage of primary health 
care and availability of skilled female health care professionals could be helpful in early detection of cancer.

\section{LIMITATIONS}

No study is free of limitations. Our participants were patients presenting to only two tertiary care hospitals of Southern Punjab that is why we were able to collect a sample of only 95 .

\section{SUGGESTIONS / RECOMMENDATIONS}

Early detection through breast self-examination and adequate treatment would result in substantial improvement in the 5-year survival rate in patients with breast cancer.

\section{CONFLICT OF INTEREST / DISCLOSURE}

The authors declare no competing conflicts of interest.

\section{ACKNOWLEDGEMENT}

We would like to thank all the patients for their cooperation.

\section{REFERENCES}

1. Rehman AS, Ali S, Khan MY, Ashraf I, Abdullah MS. Frequency of HER-2 receptors in patients with breast. Cancer. Pak J Surg. 2016;32(3):130-6.

2. Shulman LN, Willett W, Sievers A, Knaul FM. Breast cancer in developing countries: Opportunities for improved survival. J Oncol. 2010;2010:595167.

3. Noreen M, Murad S, Furqan M, Sultan A, Bloodsworth P. Knowledge and awareness about breast cancer and its early symptoms among medical and non-medical students of southern Punjab, Pakistan. Asian Pac J Cancer Prev. 2015;16(3):979-84.

4. Gulzar F, Akhtar MS, Sadiq R, Bashir S, Jamil S, Baig SM. Identifying the reasons for delayed presentation of Pakistani breast cancer patients at a tertiary care hospital. Cancer Manag Res. 2019;11:1087-96.
5. Alam S, Riaz S, Khan HA, Gardezi AB, Shehzad K, Anwar MF. Frequency of luminal $A$ and luminal $B$ breast cancers in Pakistani population. APMC 2019;13(4):296-9.

6. Begum N. Breast cancer in Pakistan: A looming epidemic. JCPSP. 2018;28(2):87-8.

7. Sayed S, Moloo Z, Ngugu A, Allidina A, Ndumia R, Mutuiri A, et al. Breast camps for awareness and early diagnosis of breast cancer in countries with limited resources: A multidisciplinary model from Kenya. Oncologist. 2016;21(9):1138-48.

8. Mahmood S, Rana TF, Ahmad M. Common determinants of $\mathrm{Ca}$ breast - a case control study in Lahore; Ann King Edward Med Coll. 2006;12(2):227-8.

9. Azhar F, Fatima T, Aqsa T, Qureshi U, Rasheed G, Khan JS Pattern of breast cancer presentation. JRMC. 2017;21(1):42-4.

10. Talpur AA, Surahio AR, Ansari A, Ghumro AA. Late presentation of breast cancer: a dilemma. J Pak Med Assoc. 2011;61(7):6626.

11. Babar F, Mahmood S, Faraz R, Yousaf A, Quader AU, Asif $H$. Epidemiology of breast cancer at Shaukat Khanum memorial cancer hospital and research center, Lahore, Pakistan. J Coll Physicians Surg Pak. 2015;25(10):738-42.

12. Unger-Saldaña $K$, Ventosa-Santaulària $D$, Miranda $A$, VerduzcoBustos $G$. Barriers and explanatory mechanisms of delays in the patient and diagnosis intervals of care for breast cancer in Mexico. Oncologist. 2018;23(4):440-53.

13. Montazeri A, Ebrahimi M, Mehrdad N, Ansari M, Sajadian A. Delayed presentation in breast cancer: a study in Iranian women. BMC Womens Health. 2003;3(1):4-6.

14. Robertson R, Campbell NC, Smith S, Donnan PT, Sullivan F, Duffy $R$, et al. Factors influencing time from presentation to treatment of colorectal and breast cancer in urban and rural areas. British Journal of Cancer. 2004;90(8):1479-85.

15. Norsa'adah B, et al. Diagnosis delay of breast cancer and its associated factors in Malaysian women. BMC Cancer. 2011;11:141.

\section{AUTHORSHIP AND CONTRIBUTION DECLARATION}

\section{AUTHORS}

Dr. Asima Luqman

Senior Registrar, Oncology

Civil Hospital, Bahawalpur Pakistan

\section{Dr. Asiya Shabbir}

Assistant Professor, Surgery

Bahawal Victoria Hospital, Bahawalpur Pakistan

\section{Dr. Muhammad Sajid}

Senior Registrar, Surgery

Bahawal Victoria Hospital, Bahawalpur Pakistan

\section{Dr. Shahid Hussain}

Assistant Professor, Surgery

Bahawal Victoria Hospital, Bahawalpur Pakistan

\section{Dr. Hafiz Muhammad Usman Ali Rizvi}

Senior Registrar, Surgery

Bahawal Victoria Hospital, Bahawalpur Pakistan

\section{Dr. Summaira Hassan}

Assistant Professor, Community Medicine

Quaid-e-Azam Medical College Bahawalpur Pakistan
Contribution to The Paper

Signatures

Data Collection

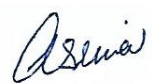

Write-up

Write-up

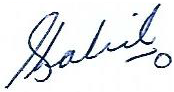

Write-up

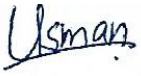

